\title{
Pelestarian bahan pustaka di museum balaputera dewa Sumatera Selatan
}

\section{Muhammad Bu'ang, Reni Anggraini, Sabrina Tri Ambarwati, dan Zahrotun Fadhila}

\begin{abstract}
This study aims to determine the obstacles and efforts to prevent the preservation of library materials, especially in ancient manuscripts and collections in the Museum Balaputera Dewa South Sumatra. From the results of research, namely interviews and observations, observations and records that Balaputera Museum God is still a lot of obstacles and barriers in terms of preservation. The method used by qualitative research in the form of data collection with observation and interview techniques. Observation here by observing the Museum Balaputera Dewa itself, while the interviews come to the chairman of the collection and conservation section Balaputera Museum of South Sumatra. From the observation that we can, Balaputera Dewa Museum has not done its job well, due to lack of fund and human resources (Human Resources) to do conservation. However, the Balaputera Dewa Museum still promotes conservation and restoration with a modest tool.
\end{abstract}

Keywords: preservation of library materials, preservation, conservation, restoration

\section{Pendahuluan}

\section{a. Latar Belakang}

Bahan pustaka adalah unsur penting dalam sistem perpustakaan, dimana bahan pustaka harus dilestarikan karena memiliki nilai informasi yang mahal. Pemeliharaan bahan pustaka tidak hanya secara fisik saja, namun juga meliputi isinya yang berbentuk informasi yang terkandung di dalamnya. Pemeliharaan merupakan kegiatan mengusahakan agar bahan pustaka yang kita punya tidak cepat mengalami kerusakan, awet, dan bisa dipakai lebih lama, demi menjaga informasi yang ada didalam bahan pustaka tersebut serta bisa dijangkau lebih banyak pembaca perpustakaan. ${ }^{1}$

\footnotetext{
${ }^{1}$ Martoatmodjo, Karmidi, Pelestarian Bahan Pustaka. (Jakarta: Universitas Terbuka, Depdikbud, 1993) h.2
} 
Kesadaran akan pentingnya pelestarian bahan pustaka baru dimulai sejak tahun 1966. Lembaga yang telah lama mengupayakan "pelestarian" ini adalah museum, arsip dan kolektor seni. Maksud pelestarian sendiri yaitu mengusahakan agar bahan pustaka tidak cepat rusak, Sedangkan tujuan pelestarian bahan pustaka sediri untuk menyelamatkan nilai informasi dokumen, menyelamatkan fisik dokumen, mengatasi kendala kekurangan ruang, dan mempercepat perolehan informasi. Museum menyimpan banyak koleksi yang memerlukan perawatan sehingga koleksi yang ada di dalam museum itu bisa dijaga dan dirawat. Museum adalah sebuah lembaga bersifat tetap, tidak mencari keuntungan, melayani masyarakat dan perkembangannya terbuka untuk umum yang memperoleh, merawat, memamerkan barang-barang pembuktian manusia dan lingkungannya untuk tujuan-tujuan studi, pendidikan dan kesenangan.

Salah satu tugas museum adalah koservasi dan restorasi, berkaitan dengan arti dan tugas Museum tersebut, melalui kegiatan konservasi dan restorasi koleksi museum bisa di perbaiki dan di awetkan sehingga koleksi yang ada di dalam museum dapat di jaga dengan baik.

Pelestarian bahan pustaka di Museum Balaputera Dewa Sumatera Selatan sendiri lebih membahas kepada konservasi dan restorasi. Sedangkan konservasi sendiri membahas tentang kegiatan dalam penyelenggaraan museum, disamping unit-unit kegiatan utama lainnnya, misalnya adminitrasi, bimbingan, studi koleksi dan preparasi. Adapun istilah yang berkaitan dengan bidang konservasi koleksi museum Balaputera Dewa seperti: pelestarian, perlindungan, perawatan, preservasi, prefentif, restorasi, repruduksi dan penyimpanan. 


\section{b. Rumusan Masalah}

1. Apa yang dimaksud dengan pelestarian bahan pustaka?

2. Faktor apa saja penyebab kerusakan bahan pustaka?

3. Koleksi apa saja yang ada di museum Balaputera Dewa ?

4. Bagaimana Preservasi yang ada di museum Balaputera Dewa ?

5. Bagaimana Koservasi dan restorasi yang ada di museum Balaputera Dewa?

6. Kendala apa saja yang dihadapi di museum Balaputera Dewa?

\section{Metodologi Penelitian}

Metode penelitian yang digunakan yaitu metode kualitatif, pengumpulan data dengan teknik observasi dan wawancara. Observasi disini dengan mengamati langsung di museum Balaputera Dewa, sedangkan wawancara mendatangi ketua dari bagian-bagian koleksi dan konservasi museum Balaputera Dewa Sumatera Selatan.

\section{Pembahasan}

\section{a. Pengertian Pelestarian Bahan Pustaka}

Pelestarian adalah salah satu kegiatan yang tidak dapat dipisahkan dalam ruang lingkup manajemen perpustakaan. Istilah pelestarian kedengarannya mungkin sangat sederhana, namun memiliki pengertian yang luas. Dalam bahasa Indonesia, istilah pelestarian berasal dari bahasa sangsekerta, lestari yang berarti terpelihara, sedangkan dalam bahasa Inggris, istilah pelestarian disebut dengan preservasion yang memiliki kata dasar preserve. Artinya dengan preservasi dapat menjaga bahan pustaka yang ada sehingga bahan pustaka dapat bertahan lama. Semua unsur pengelolaan, keuangan, penyimpanan, alat-alat bantu, ketenagakerjaan, maupun metode yang digunakan untuk melestarikan bahan pustaka, dokumentasi, arsip, maupun informasi yang dikandungnya.

Istilah preserve bersumber dari bahasa latin, prae dan servare. Prae berarti 'sebelum', dan servare berarti to save, untuk 
menyelamatkan. Apabila digabungkan, istilah preserve dapat dimaknai sebagai upaya untuk menjaga dari kerusakan. ${ }^{2}$ Selanjutnya tujuan pelestarian bahan pustaka adalah melestarikan kandungan informasi bahan pustaka dengan alih bentuk menggunakan media lain atau melestarikan bentuk aslinya selengkap mungkin untuk dapat digunakan secara optimal. ${ }^{3}$

Jadi, dapat kita simpulkan bahwa pelestarian atau preservasi adalah suatu kegiatan untuk memperlambat keruasakan bahan pustakan dan membuat bahan pustaka tersebut lebih awet dan dapat bertahan lama. Dengan kata lain pelestarian adalah suatu kegiatan yang tidak hanya fisik tetapi juga strategis dalam segi perbaikan dan perlindungan.

\section{b. Faktor Penyebab Kerusakan Bahan Pustaka}

Pada dasarnya terdapat dua jenis kegiatan dalam kegiatan pelestarian bahan pustaka, yaitu mencegah terjadinya kerusakan dan memperbaiki kerusakan-kerusakan tersebut. Untuk dapat melakukan kedua kegiatan tersebut secara maksimal, maka kita perlu mengetahui pula faktor penyebab kerusakannya.

Dalam hal ini, Bafadal membagi faktor penyebab kerusakan menjadi dua, yaitu :

1. Ulah manusia atau minuman.

2. Faktor alamiah. Misalnya, kelembaban udara, air, api, jamur, debu, sinar matahari dan serangga. ${ }^{4}$

Di museum Balaputera Dewa, kerusakan sering terjadi karena disebabkan oleh factor alamiah, seperti halnya kelembaban udara yang ada didalam ruangan, banyaknya debu-debu yang masuk melalu pentilasi ruangan yang kurang baik.

\footnotetext{
${ }^{2}$ Yeni Budi Rachman, Preservasi dan Koservasi Bahan Pustaka. (Depok: Rajawali Pers, 2017), h.3-5

${ }^{3}$ Sulistyo-Basuki, Pengantar Ilmu Perpustakaan (Jakarta: Gramedia Pustaka Utama, 1991), hlm. 271.

${ }^{4}$ Ikakrismayani, "Analisis pelestarian koleksi bahan pustaka Tercetak pasca bencana banjir di perpustakaan Ceria Desa jl eper, Kecamatan mijen, Kabupaten Demak pada tahun 20113" Vol.4 No. 3 h. 4
} 


\section{c. Museum}

Pengertian Museum seperti yang telah dirumuskan ICOM (International Council Of Muzeum) suatu badan kerjasama professional di bidang permuseuman dari seluruh dunia, yaitu “ Museum adalah sebuah lembaga tetap yang bersifat tetap, tidak mencari keuntungan, melayani masyarakat dan perkembangannya terbuka untuk umum yang memperoleh, merawat, memamerkan barang-barang pembuktian manusia dan lingkungannya untuk tujuan-tujuan studi, pendidikan dan kesenangan. ${ }^{5}$

Berdasarkan arti dan tugas museum yang disusun oleh ICOM, ada beberapa hal yang ditekankan dari fungsi museum, antara lain;

1. Pengumpulan dan pengamanan warisan alam dan budaya.

2. Dokumentasi dan penelitian ilmiah.

3. Konservasi dan Restorasi.

4. Penyebaran dan pemerataan ilmu dan umum.

5. Pengenalan dan penghayatan kesenian.

6. Pengenalan kebudayaan antar daerah dan bangsa.

7. Visuallisasi warisan alam dan budaya.

8. Cermin pertumbuhan peradaban umat manusia.

9. Pembangkit rasa bertaqwa dan bersyukur kepada Tuhan Yang Maha Esa. 6

\section{d. Koleksi Museum}

Museum Negeri Sumatera Selatan "Balaputer Dewa" merupakan museum umum yang koleksinya terdiri dari 10 (sepuluh) jenis koleksi dengan bahan beragam yaitu :

1. Geologika, yaitu benda koleksi yang merupakan objek disiplin ilmu geologi antara lain meliputi batuan, mineral, fosil dan bendabenda bentukan alam lainnya (permata, granit, andesit)

2. Biologika, yaitu benda koleksi yang masuk katagori benda objek penelitian atau dipelajari oleh disiplin ilmu biologi, antara lain

\footnotetext{
${ }^{5}$ Amir Sutaarga, "Pedoman Penyelenggaraan dan Pengelolaan Museum", (Direktorat Permuseuman Direktorat Jendral Kebudayaan, P\&K, 1983) h. 18-19

${ }^{6}$ ICOM (Code of Ethics For Museums, 2006. h.14
} 
berupa tengkorak atau rangka manusia, tumbuh-tumbuhan dan hewan.

3. Etnografika, yaitu benda koleksi yang menjadi objek penelitian Antropologi. Benda-benda tersebut merupakan hasil budaya atau menggambarkan identitas suatu etnis.

4. Arkeologika, yaitu benda koleksi yang merupakan hasil budaya manusia masa lampau yang menjadi objek penelitian Arkeologi. Benda-benda tersebut merupakan hasil tinggalan budaya sejak masa prasejarah sampai masuknya pengaruh budaya barat.

5. Historika, yaitu benda koleksi yang mempunyai nilai sejarah dan menjadi objek penelitian ilmu Sejarah serta meliputi kurun waktu sejak masuknya budaya barat sampai sekarang. Benda-benda ini pernah digunakan untuk hal-hal yang berhubungan denga suatu peristiwa sejarah, yang berkaitan dengan suatu organisasi masyarakat (contohnya Negara atau kelompok, dll)

6. Numismatika dan Heraldika

- Numismatika, yaitu setiap mata uang atau alat tukar yang sah

- Heraldika, yaitu setiap tanda jasa, lambang dan tanda pangkat resmi (termasuk cap/stempel).

7. Filologika, yaitu benda koleksi yang menjadi objek penelitian Filologi, berupa naskah kuno, naskah tulis tangan, yang berisi tentang sesuatu hal atau peristiwa.

8. Keramologika, yaitu benda koleksi yang dibuat dari bahan tanah liat yang dibakar (baked clay) berupa barang pecah belah.

9. Seni Rupa, yaitu benda koleksi seni yang mengekspresikan pengalaman artistik manusia melalui objek dua atau tiga dimensi.

10. Teknologika, yaitu setiap benda / kumpulan yang menggambarkan perkembangan teknologi yang menonjol berupa peralatan dan atau hasil produksi yang dibuat secara masal oleh suatu industri atau pabrik. ${ }^{7}$

7 Pemerintah Provinsi Sumatera Selatan Dinas Kebudayaan dan Pariwisata Museum Negeri Sumatera Selatan, " Koservasi dan Restorasi Koleksi” (Paper present at Laporan Koservasi dan Restotasi Museum Negeri Sumatera Selatan Tahun Anggaran 2016), h.1-3 


\section{e. Pedoman Kegiatan Penyempurnaan Tata Pameran (Preservasi) Museum}

\section{Balaputera Dewa}

Dalam kegiatan preserpasi atau penyempurnaan tata pameran koleksi museum harus diperhatikan berbagai hal teknis permuseuman, yakni jenis pameran, prinsip tata pameran, factor koleksi, factor penyajian dan metode penyajian. Teknis permuseuman tersebut harus dipahami agar memperoleh hasil penataan secara maksimal. 8

\section{Jenis-jenis Pameran}

Dilihat dari tempat dan jangka waktu pelaksanaan pameran museum dibedakan manjadi tiga.

a. Pameran Tetap

Pameran tetap diselenggarakan di lokasi museum dengan jangka waktu sekurang-kurangnya lima tahun. Namun. Sejalan dengan kemajuan zaman dan teknologi sebelum habis masa itu dapat dilakukannya renovasi.

b. Pameran Temporer/Pameran Khusus

Pameran ini dilaksanakan di museum dengan variasi jangka waktu tertentu mulai dari satu minggu hingga satu tahun. Waktu penyelenggaraannya biasanya diselaraskan dengan momen-momen tertentu, seperti peringatan hari-hari besar nasional atau hari jadi suatu kota.

c. Pameran Keliling

Pameran ini diselenggarakan di luar lokasi museum, dalam jangka waktu tertentu dengan tema khusus, dipamerkan atau dikelilingkan dari satu tempat ke tempat lainnya.

Di museum Balaputera Dewa preservasi yang dilakukan lebih mengarah pada tata pameran yang ada, sebab di museum Balaputera Dewa preservasi yang dilakukan yaitu untuk

8 Pemerintah Provinsi Sumatera Selatan Dinas Kebudayaan dan Pariwisata Museum Negeri Sumatera Selatan, "Preservasi" (Paper present at Laporan Preservasi (Penyempurnaan Tata Pameran) Museum Negeri Sumatera Selatan Tahun Anggaran 2017), h.6 
memperindah ruangan-ruangan, sehingga pengunjung dapat lebih merasa nyaman di dalam museum.

\section{f. Koservasi dan Restorasi}

Koservasi mempunyai pengertian sebagai suatu tindakan untuk melindungi dari bahaya atau kerusakan, memelihara atau merawat sesuatu dari gangguan, kemusnahan, atau keausan. Sedangkan restorasi adalah suatu tindakan memperbaiki bahan pustaka yang telah rusak. ${ }^{9}$

Konservasi koleksi museum artinya melakukan kegiatan untuk melestarikan keberadaan dan nilai-nilai yang terdapat pada koleksi museum. Koleksi museum adlah benda cagur budaya yang memiliki nilai ilmu pengetahuan, kesenian, serta nilai keagamaan, nilai histori, dan sebagainya. ${ }^{10}$

\section{g. Sistem dan Teknik Koservasi}

\section{Sistem Koservasi}

Koleksi museum yang diproses di laboratorium konservasi dilaksanakan dengan aturan kerja sebagai berikut :

a. Perencanaan Konservasi

Sebelum melaksanakan pekerjaan konservasi, terlebih dahulu petugas konservasi melakukan penyusunan rencana kerja, jadwal kerja dan jumlah tenaga kerja yang akan melaksanakan pekerjaan tersebut serta menyiapkan sarana dan prasarana yang dibutuhkan sesuai dengan tingkat kerusakan koleksi, seperti bahan dan obat-obatan kimia, apabila di laboratorium belum mempunyai atau telah habis jenis bahan kimia yang akan digunakan, maka petugas konservasi melakukan penyusunan rencana pengadaan bahan kimia yang dibutuhkan lengkap dengan perincian biaya, selanjutnya diajukan kepada kepala museum untuk mendapatkan persetujuan.

b. Pengiriman koleksi untuk dikonservasi

\footnotetext{
${ }^{9}$ V.J. Herman, Pedoman Koservasi Koleksi Museum, (Jakarta: Direktori Permusiuman Departemen Pendidikan dan Kebudayaan, 1989), h. 6

${ }^{10}$ Wahono "Koservasi Benda Budaya di Museum Merupakan Realisasi Sistem Manajemen" Vol. 2 No.2 h. 94
} 
1) Semua koleksi yang akan dikonservasi dicatat didalam daftar khusus koleksi untuk dikonservasi, yang mencantumkan nama benda, nomor koleksi dan identitas lainnya.

2) Daftar tersebut dibuat oleh petugas koleksi untuk dikirimkan kepada petugas konservasi dengan tembusan kepada kepala museum melalui kepala seksi

3) Setelah menerima pengiriman daftar dan koleksi yang akan dikonservasi petugas konservasi melakukan pendataan ulang, yang terlebih dahulu mencantumkan nomor agenda.

c. Tahapan Kerja Konservasi

Kegiatan konservasi koleksi dilakukan dengan tahapan sebagai berikut;

1) Pemeriksaan dan pencatatan koleksi

2) Pemotretan koleksi sebelum dilakukan tindakan konervasi. Pemotretan dengan memperhatikan dan mencatat posisi obyek, waktu, distansi, diafragma, kecepatan, asa film, merk film dan kamera.

3) Melakukan kerja perawatan dan pengawetan terhadap koleksi

4) Pemotretan kembali setelah koleksi selesai dikonservasi sesuai dengan catatan keadaan pemotretan pertama

5) Penyusunan laporan pekerjaan konservasi yang meliputi bahan kimia, waktu kerja, pelaksana kerja dan sebagainya.

6) Pemberian nomor inventaris koleksi bagai koleksi yang hilang nomor inventerisnya.

7) Pengiriman kembali semua koleksi ke kelompok koleksi, sesuai dengan prosedur dan tata kerja yang berlaku.

d. Pemeliharaan sarana dan prasarana laboratorium konservasi Pemeliharaan yang dimaksud dalam hal ini :

1) Pemeliharaan fisik bangunan laboratorium konservasi, baik bagian dalam maupun bagian luar, bekerjasama dengan urusan rumah tangga

2) Pemeliharaan barang-barang dilaboratorium konservasi yang meliputi perangkat kerja baik alat-alat elektronika maupun non elektronik. 
3) Penyimpanan bahan kimia dengan memperhatikan keamanan, keselamatan dan kesehatan kerja.

4) Penyimpanan arsip yang meliputi buku laporan, hasil pemotretan, hasil penelitian, lembar proses kerja, data laboratorium dan sebagainya.

e. Inspeksi kegiatan konservasi

Inspeksi dilakukan sesuai dengan atauran pelaksanaan kegiatan konservasi koleksi museum. Dengan adanya inspeksi dapat diketahui apakah terjadi hambatan, penyimpanan, kesalahan atau ketidak sesuaian.

f. Pertanggungjawaban kegiatan konservasi

Untuk mempertanggungjawabkan tugas dan kewajibannya, petugas konservasi mambuat laporan, baik laporan setelah selesai pelakasaan koservasi maupun laporan triwulan, tengah tahunan dan tahunan. Laporan memuat pemakaian peralatan laboratorium, penggunaan bahan kimia, jumlah penerimaan peralatan dan bahan kimia, serta jumlah koleksi yang telah dikonservasi. ${ }^{11}$

\section{Tindakan konservasi}

Berdasarkan atas tujuan konservasi dapat dibedakan ke dalam dua langkah :

a. Langkah prefentif.

Metode ini dimaksudkan sebagai upaya untuk mencegah terjadinya kerusakan terhadap koleksi.

Langkah prefentif meliputi ;

1) Pengendalian terhadap kelembaban dan suhu udara

Hal-hal yang sangat penting untuk diperhatikan ialah kondisi kelembaban dan suhu udara yang ada di ruang pameran dan gudang koleksi. Untuk mengetahui hal itu dapat menggunakan alat pencatat kelembaban udara dan pencatat suhu udara.

2) Pengaturan terhadap pencahayaan

Cahaya yang digunakan untuk penerangan didalam ruang pameran dan gudang koleksi diselaraskan dengan kondisi dan jenis koleksi. Dalam hal ini ada dua sumber cahaya yang mungkin digunakan, yaitu

${ }^{11}$ M. Yusuf Rizal, Pengetahuan Dasar Koservasi Koleksi, (Palembang: Dinas Pendidikan Nasional Prov. Sumatera Selatan, 2004),h. 6-7 
cahaya alam dan cahaya buatan (lampu). Pada cahaya terdapat dua unsur yang dapat merusakan koleksi yaitu radiasi ultraviolet dan intensitas cahaya. Rdiasi ultraviolet dapat diketahui dengan menggunakan alat UV Monitor, baik yang berasal dari cahaya alam maupun cahaya buatan (lampu ruangan), sedangkan Lux Meter alat untuk mengukur intensitas cahaya. Penggunaan cahaya sebagai penerangan pada ruangan pameran perlu dilakukan pengaturan yang tepat, khususnya untuk ruangan koleksi jenis benda organic. Radiasi ultraviolet yang boleh tersisa didalam penyinaran pada ruangan pameran yang terpajang koleksi benda organic, anata $30-80 \mathrm{MW} / \mathrm{Cm}$. Bila cahaya dalam ruangan pameran melebihi batas-batas seperti tersebuat diatas, sumber cahaya perlu ditutup dengan kaca buram (maat glass) sebagai filter radiasi ultraviolet. Sedangkan intensitas cahaya yang perlu dipersyaratkan yaitu anatara 50-150 Lux.

3) Cara pengangkutan koleksi yang dikonservasi

Koleksi yang diterima oleh kelompok konservasi segera dibawa ke laboratorium konservasi lengkap dengan suarat pengantar dan daftar koleksi dari kelompok koleksi. Pengiriman koleksi dari tempat penyimpanan ke laboratorium konservasi harus dengan hati-hati sekali. Bagi benda-benda yang dibawa dengan menggunakan gerobak dorong paling tidak beroda dua. Bagi koleksi yang kondisinya amat lemah harus diangkat secara perlahan, kemudian ditaruh pada alat pembawa (gerobak dorong) dengan alas yang lunak agar mengurangi goncangan yang dapat menimbulkan kerusakan baru.

4) Pengawetan koleksi

Dilakukan pengawetan dengan bahan kimia pengawet, penguat, pengisi atau penghambat. Untuk melindungi koleksi dari pengaruh klimatik dan hama/penyakit bologis perlu pelapisan dengan bahan pelindung. Bila koleksi terlalu lemah atau rawan perlu dibuat tiruannya, sedang koleksi aslinya disimpan pada tempat yang layak.

b. Langkah Kuratif/Refresif

Metode ini dimaksudkan sebagai upaya untuk pengobatan bagi koleksi yang benar-benar mengalami gangguan kerusakan / penyakit.

Langkah represif meliputi : 
1) Pembasmian hama/penyakit dengan bahan fumigan atau bahan lainya.

2) Pembersihan kotoran/debu dengan polutan yang menempel memperburuk koleksi

3) Penghilangan penyakit dengan bahan kimia yang direkomendasikan

4) Restorasi koleksi bagi koleksi yang rusak atau hilang salah satau atau beberapa bagiannya.

Ada beberapa persyaratan yang perlu diperhatikan dalam pelaksanaan metode ini, yaitu ;

1) Penyembuhan koleksi harus didasari atas hasil pengamatan mengenai bahan koleksi dan penyebab kerusakannya.

2) Penggunaan bahan kimia harus diperhitungkan secara teliti mengenai jenis, perbandingan jumlah campuran (dosis) agar idak merusak bahan dan warna koleksi serta tidak terjadi kesalahan yang fatal.

3) Penyembuhan benda-benda tertentu, apabila cukup dengan menggunakan panas $60 \mathrm{C}$, tidak menggunakan bahan kimia lain.

4) Tidak boleh menggunakan alat laboratorium dan bahan kimia ynag berlawanan dengan ketentuan..

5) Benda-benda koleksi museum yang telah dikonservasi menjadi baik dan tahan terhadap gangguan. ${ }^{12}$

\section{h. Koservasi dan Restorasi Koleksi Museum Balaputera Dewa}

Dalam konservasi dan restorasi koleksi Museum Negeri Sumatera Selatan "Balaputra Dewa", akan dilakukan oleh staf Museum Negeri Sumatera Selatan yang bertugas di bagian Konservasi dengan dibantu oleh petugas koleksi dan preparasi. Agar konservasi koleksi berjalan dengan baik dan efektif, dilakukanlah beberapa tahap pengerjaannya yaitu; persiapan konservasi, pelaksanaan konservasi dan sesudah tindakan konservasi.

\footnotetext{
12 M. Yusuf Rizal, Pengetahuan Dasar Koservasi Koleksi, (Palembang: Dinas Pendidikan Nasional Prov. Sumatera Selatan, 2004),h. 8-9
} 


\section{Persiapan Konservasi}

Akan dilakukan beberapa tindakan sebelum konservasi berlangsung melalui beberapa proses persiapan-persiapan antara lain:

a. Analisis

Disini konsevator akan melakukan penilaian, pemeriksaan, meneliti ataupun meninjau langsung koleksi atau benda yang akan dikonservasi.

b. Pengumpulan Koleksi

Setelah dianalisis, konsevator mengumpulkan koleksi yang terkena penyakit dan yang mengalami kerusakan.

c. Pembelian Bahan-Bahan

Bahan-bahan untuk mengkonservasi (restorasi) koleksi agar terlaksana dengan baik dan efektif harus tersedia terlebih dahulu karena inilah hal yang terpenting untuk pelaksanaan berlangsungnya konservasi, jika tidak konservasi akan terhenti karena terkendala minimnya bahan-bahan untuk mengkonservasi (restorasi).

Adapun persiapan bahan-bahan konservasi adalah:

a. Pembelian bahan kimia atau obat-obatan

b. Pembelian alat-alat kebersihan

c. Pembelian peralatan bengkel

d. Pembelian bahan bangunan

e. Pembelian ATK dan

f. Untuk dokumentasi

d. Pendataan Koleksi

Melakukan pendataan identitas benda, serta kondisi pada koleksi yang terkena penyakit atau rusak. Pendataan ini akan berguna sekali, karena koleksi akan mudah dikontrol untuk perawatan selanjutnya.

e. Dokumentasi persiapan

Pada awal persiapan konservasi ini telah dilakukan pemotretan saat melakukan analisis langsung pada koleksi, saat pengumpulan 
atau pengelompokkan koleksi dan pada saat koleksi di data identitasnya.

\section{Pelaksanaan Konservasi}

Setelah tahap awal sudah kita persiapkan, maka selanjutnya dilakukan tindakan konservasi (restorasi) yang langsung menyentuh benda koleksi yang terkena penyakit maupun benda koleksi yang mengalami kerusakan.

a. Pembagian Jenis dan Bahan Koleksi

Pada pelaksanaan ini koleksi akan dipisah berdasarkan bahan atau materialnya yaitu koleksi yang berbahan organik, anorganik dan koleksi khusus.

b. Pengerjaan Konservasi

Pada tindakan ini, koleksi sudah siap untuk dikonservasi. Pengerjaan konservasi harus lebih berhati-hati dengan tidak menyimpang dari tindakan dasar dalam konservasi koleksi karena jika tidak teliti dapat menyebabkan koleksi akan bertambah rusak.

Setelah pelaksanaan konservasi selesai dikerjakan dengan baik, maka koleksi kembali didata dan untuk dikembalikan ketempatnya pada ruang penyimpanan (storage) serta pada ruang koleksi tersebut dipamerkan.

Dari hasil wawancara yang dilakukan informasi yang didapat yaitu bahwa cara melalukan konservasi pada koleksi pameran di museum Balaputera Dewa bisa dilakukan dengan cara menggunakan bahan-bahan yang alami, seperti campuran kayu manis dan pelepah buah pisang yang masih muda dengan perbandingan 1:1 setelah melakukan pencampuran tersebut, bisa diaplikasikan langsung pada beberapa koleksi pameran yang berbahan kayu, selain itu di museum Balaputera Dewa melakukan restorasi dengan memperbaiki koleksi-koleksi yang rusak sehingga bisa terlihat seperti baru lagi.

\section{i. Manfaat Koservasi dan Restorasi di Museum Balaputera Dewa}


Kegiatan Konservasi (Restorasi) Koleksi Museum Negeri Sumatera Selatan "Balaputra Dewa" sangat memberikan manfaat pada koleksi, yaitu :

- Agar semua koleksi yang ada di Museum Negeri Sumatera Selatan terjaga kelestariannya.

- Agar koleksi terawat dengan baik.

- Supaya terhindar dari kerusakan, kehancuran dan kemusnahan yang berakibat fatal.

- Agar koleksi tetap utuh, sehat, aman dan lebih awet.13

\section{j. Kendala Yang Dihadapi di Museum Balaputera Dewa}

Di museum Balaputera Dewa kendala yang dihadapi yaitu koservasi dan restorasi dilakukan hanya satu tahun sekali, kemudian kurangnya tenaga ahli dan dana dalam melakukan sistem fumigasi sehingga fumigasi tidak pernah dilakukan lagi di museum Balaputera Dewa.

\section{Penutup}

\section{a. Kesimpulan}

Dapat kita simpulkan bahwa pelestarian atau preservasi adalah suatu kegiatan untuk memperlambat keruasakan bahan pustakan dan membuat bahan pustaka tersebut lebih awet dan dapat bertahan lama. Dengan kata lain pelestarian adalah suatu kegiatan yang tidak hanya fisik tetapi juga strategis dalam segi perbaikan dan perlindungan. Di museum Balaputera Dewa preservasi yang dilakukan lebih mengarah ke tata pameran, sedangkan koservasi dan restorasi yang dilakukan dengan bebagai macam cara agar koleksi dapat bertahan lama. Selanjutnya kerusakan yang terjadi di museum banyak terjadi akibat factor alamiah, yaitu dari segi kelembapan udara dan debu-debu yang menempel pada koleksi.

\footnotetext{
13 Pemerintah Provinsi Sumatera Selatan Dinas Kebudayaan dan Pariwisata Museum Negeri Sumatera Selatan, "Koservasi dan Restorasi Koleksi" (Paper present at Laporan Koservasi dan Restotasi Museum Negeri Sumatera Selatan Tahun Anggaran 2016), h.6-9
} 


\section{b. Saran}

Menurut kami, Museum Balaputera Dewa ini dari segi koleksi sangat baik dengan berbagai macam daerah yang ada. Tetapi, dalam segi preservasi (pelestarian) mereka belum memaksimalkannya dengan baik. Diharapkan kedepannya agar Museum tersebut lebih memperhatikan koleksi-koleksi dengan mengadakan preservasi secara rutin agar koleksi-koleksi yang ada disana bisa terawat dan terpelihara dengan baik.

\section{Daftar Pustaka}

Yeni Budi Rachman. (2017). Preservasi dan Koservasi Bahan Pustaka. Depok: Rajawali Pers.

Ikakrismayani, "Analisis pelestarian koleksi bahan pustaka Tercetak pasca bencana banjir di perpustakaan Ceria Desa j1 eper, Kecamatan mijen, Kabupaten Demak pada tahun 2013"

ICOM (2006). "Code of Ethics For Museums".

Pemerintah Provinsi Sumatera Selatan Dinas Kebudayaan dan Pariwisata Museum Negeri Sumatera Selatan. (2017) “ Koservasi dan Restorasi Koleksi”. Paper present at Laporan Koservasi dan Restotasi Museum Negeri Sumatera Selatan Tahun Anggaran 2016.

Pemerintah Provinsi Sumatera Selatan Dinas Kebudayaan dan Pariwisata Museum Negeri Sumatera Selatan. (2017) “ Preservasi" (Paper present at Laporan Preservasi (Penyempurnaan Tata Pameran) Museum Negeri Sumatera Selatan Tahun Anggaran 2017.

V.J. Herman (1989). Pedoman Koservasi Koleksi Museum, Jakarta: Direktori Permusiuman Departemen Pendidikan dan Kebudayaan.

M. Yusuf Rizal. (2004) Pengetahuan Dasar Koservasi Koleksi, Palembang: Dinas Pendidikan Nasional Prov. Sumatera Selatan.

Martoatmodjo, Karmidi. (1993). Pelestarian Bahan Pustaka. Jakarta: Universitas Terbuka, Depdikbud.

Sulistyo-Basuki. (1991). Pengantar Ilmu Perpustakaan Jakarta: Gramedia Pustaka Utama.

Amir Sutaarga. (1983). "Pedoman Penyelenggaraan dan Pengelolaan Museum", Direktorat Permuseuman Direktorat Jendral Kebudayaan, P\&K.

Wahono "Koservasi Benda Budaya di Museum Merupakan Realisasi Sistem Manajemen" 
